\title{
Degradation study of mesotrione and other triketone herbicides on soils and sediments
}

\author{
Hanna Barchanska $^{1}$ • Aleksandra Kluza ${ }^{1}$ - Karolina Krajczewska ${ }^{1} \cdot$ Joanna Maj $^{1}$
}

Received: 17 February 2015 / Accepted: 16 June 2015 /Published online: 3 July 2015

(C) The Author(s) 2015. This article is published with open access at Springerlink.com

\begin{abstract}
Purpose Triketone compounds are considered to be less stable in the ecosystems in comparison with other herbicides. However, their degradation processes in environment are under investigation as both parents and degradation products can exhibit toxicity on non-target organisms. The objective of this research was to investigate the degradation of triketone herbicides: mesotrione, sulcotrione, and tembotrione, as well as their degradation products in soils and sediments.

Materials and methods The degradation studies were conducted in soil and sediment samples with different physicochemical properties. All experiments were conducted under standard experimental conditions; therefore, it was possible to assess the influence of $\mathrm{pH}$, organic carbon (OC) content of soils and sediments, and the sunlight on the stability of triketones and their degradation products. The conditions of extraction and chromatographic determination were optimized for the determination of triketones and their degradation products in laboratory-spiked sediment and soil samples. Results and discussion The triketone degradation products exhibited higher stability in soil and sediment samples in comparison with parent herbicides. Soil microorganisms accelerated the degradation of all investigated compounds. In
\end{abstract}

Responsible editor: Hailong Wang

Electronic supplementary material The online version of this article (doi:10.1007/s11368-015-1188-1) contains supplementary material, which is available to authorized users.

Hanna Barchanska

hanna.barchanska@polsl.pl

1 Department of Inorganic, Analytical Chemistry and Electrochemistry, Faculty of Chemistry, Silesian University of Technology, B.Krzywoustego 6 Str, 44-100 Gliwice, Poland alkaline soil and sediments, all analytes exhibited higher stability in comparison with the acidic sorbents. The influence of OC content in sorbents was not evident. Photodegradation was the main path of triketones decomposition in soils and sediments.

Conclusions Since the stability of triketone herbicides may be significant, depending on the environmental conditions, the monitoring of the concentration of these compounds and in particular their degradation products should be conducted under the field conditions.

Keywords Degradation $\cdot$ Mesotrione $\cdot$ Sediment $\cdot$ Soil . Sulcotrione $\cdot$ Triketone herbicides

\section{Introduction}

Triketones are relatively a new group of herbicides belonging to the $\beta$-triketone family and are recommended as a replacement of atrazine in European Union countries. They are post-emergence maize-selective herbicides. Triketones are chemically derived from leptospermone (2,2,4,4-tetramethyl-6-(3methylbutanoyl)cyclohexane-1,3,5-trione), a natural phytotoxin of the Californian bottlebrush plant (Callistemon citrinus). They were developed to minimize adverse effects on the environment. However, the investigation of these pesticide degradation processes occurring in the environment is of high interest, as both parent and generated byproducts can exhibit toxicity (neurotoxicity, endocrine disruption) on non-target organisms, such as algae, fish, invertebrate, etc.; these compounds have also the potential to alter benthic community structure in agriculture estuaries (Anderson et al. 2003; SanchezAvila et al. 2011; Menager and Sarakha 2013; Smalling 
et al. 2013; Barchanska et al. 2014; Mountacer et al. 2014). The biodegradation process of triketones has been discussed in depth. However, in natural conditions, the degradation of organic pollutants is due to a combination of several processes, among them photochemical reactions involving sunlight play the most significant role (Chaabane et al. 2008; Batisson et al. 2009; Crouzet et al. 2010; Mountacer et al. 2014; Murati et al. 2014).

The commonly used synthetic $\beta$-triketone herbicides are mesotrione (MES; 2-(4-mesyl-2-nitrobenzoyl)-1,3cyclohexanedione), sulcotrione (SUL; 2-[2-chloro4-(methylsulfonyl)benzoyl]-1,3-cyclohexanedione), and tembotrione (TEMB; 2-\{2-chloro-4-(methylsulfonyl)-3-[(2, 2,2-trifluoroethoxy)methyl]benzoyl\}-1,3-cyclohexanedione, $2-\{2-\mathrm{c}$ h 1 o r o $-4-\mathrm{m}$ e s y $1-3-[(2,2,2-$ trifluoroethoxy)methyl]benzoyl $\}$ cyclohexane-1,3-dione). MES, a member of the triketone group, was the second topselling herbicide in the world in 2010 (Cropnosis Agrochemical Database 2010). Triketones are used as pre- and post-emergence herbicides mainly in maize cultivation. All triketone herbicides are weak acids, existing in molecular form at low $\mathrm{pH}$, in anionic form at neutral or alkaline $\mathrm{pH}$. The latter form is more resistant to hydrolysis and photolysis processes. In Table 1, chemical structures, $\mathrm{p} K_{\mathrm{a}}$, and $\log \mathrm{P}$ of the investigated herbicides and their byproducts are presented.

Table 1 Structures, spectrum, $\mathrm{p} K_{\mathrm{a}}$, and $\log \mathrm{P}$ values of the investigated compounds

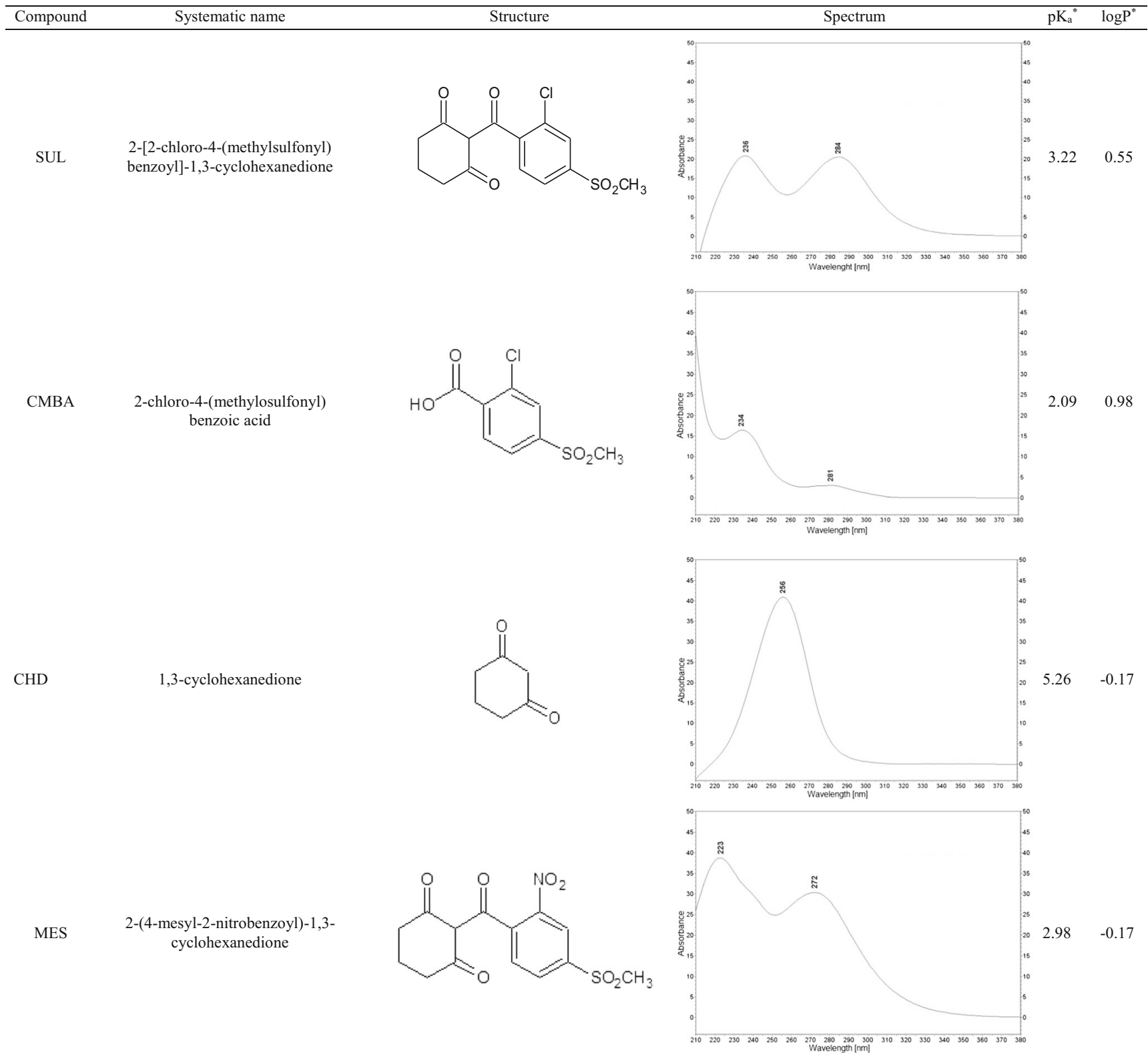


Table 1 (continued)

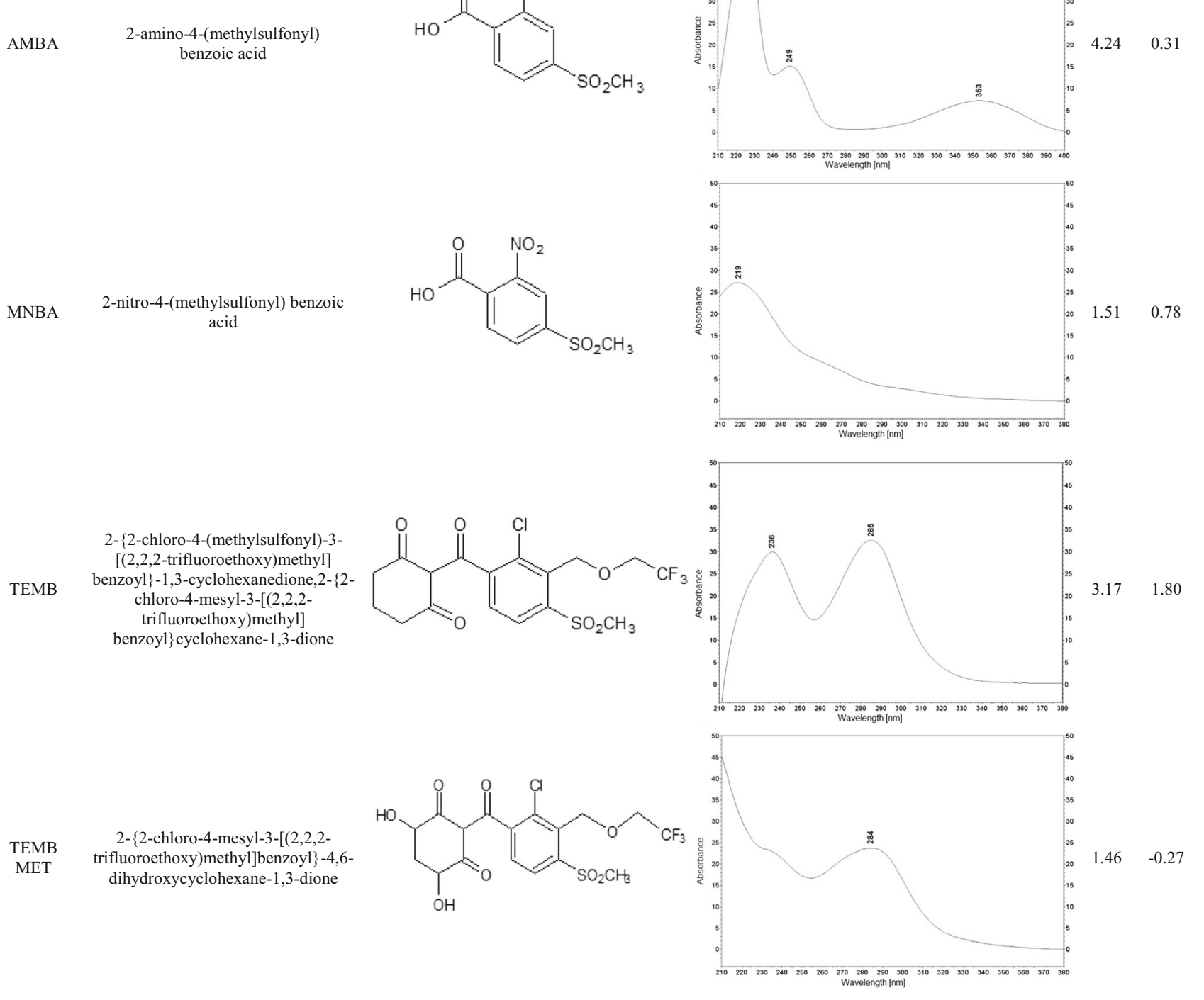

${ }^{a}$ Octanol-water partition constants and ionization constant were obtained from ACD/Labs (SciFinder)

Two MES degradation products, 2-amino-4methylsulfonylbenzoic acid (AMBA) and 4-methylsulfonyl-2nitrobenzoic acid (MNBA), which are reduced to AMBA, have been identified in soils. AMBA exhibits higher toxicity than the parent compound (Bonnet et al. 2008). According to Chaabane et al. (2007, 2008), SUL degrades according to two different pathways both in soil and water. It disintegrates into 3cyclohexanedione (CHD) and 2-chloro-4-mesyl benzoic acid (CMBA), and under particular conditions (soil pH below 6.6), a derivative of phenylheptanoic acid (PHD). TEMB degrades into several products, depending on the conditions $(\mathrm{pH}$, presence of microorganism, sunlight, OC content). One of the main degradation product of this herbicide is 2- $\{2$-chloro-4-mesyl-3-[(2,2, 2-trifluoroethoxy)methyl]benzoyl $\}$-4,6-dihydroxycyclohexane- 1,3-dione (TEMB MET) (Calvayrac et al. 2013). In spite of numerous studies on triketones, the stability of their degradation products in the environment has not yet been fully evaluated.

Soil is a non-renewable resource vital to human activities and ecosystem survival. However, the capacity of soil to perform its broad variety of crucial functions might be reduced, mainly due to chemical contamination by pesticides (Mamy et al. 2011).

Several studies reported on the transformation of pesticides at the surface of soils or clays (Asensio-Ramos et al. 2010; Rani and Juwarker 2010; Feria-Reyes et al. 2011; Hutta et al. 2011; Lu 2011; Barchanska et al. 2013; $\mathrm{Li}$ et al. 2013). The transformation of triketone in soils is also an object of investigation (Chaabane et al. 2005, 2008; Cherrier et al. 2005; Murati et al. 
2012); however, the studies have been conducted on individual compounds and/or under different experimental conditions, which hinders the comparison of the results and thereby the assessment of triketones and their degradation products stability in soils and sediments.

The aim of this study was to investigate stability of both triketone herbicides and their degradation products in soils and sediments with different physicochemical properties. All experiments were conducted under standard conditions, which enabled the assessment of the influence of $\mathrm{pH}$, organic carbon content of sorbents, the sunlight, and the presence of microorganisms on the stability of triketones. Particular attention was paid to determine the stability of the degradation products of triketones, since there is almost no research concerning the stability of these compounds in soils and sediments.

\section{Materials and methods}

\subsection{Instrumentation and chemicals}

The qualitative and quantitative analyses of herbicides were performed using a liquid chromatograph (LC) Merck Hitachi equipped with a L-6200A pump, D-7000 interface, DAD-L4500A diode array detector, and L-7360 oven. LiChroCART 125-3 Purospher STAR RP-18e at $5 \mu \mathrm{m}$ with appropriate precolumn was applied.

Solid-phase extraction was performed using a J.T. Baker (Holland) vacuum manifold. Solid-phase extraction cartridge columns were obtained from Agilent, Germany (silica gel modified with octadecyl chains (Bond Elut ENV) $500 \mathrm{mg}$, $6 \mathrm{ml}$ ); J.T. Baker, Holland (styrene-divinylbenzene (SDB), $500 \mathrm{mg}, 6 \mathrm{ml}$ ); and Waters, USA (copolymer styrene- $N$ vinylpyrrolidone (Oasis HLB), $500 \mathrm{mg}, 6 \mathrm{ml}$ ).

Standards of herbicides and their degradation products (purity $99.8 \%$ ) were supplied by Sigma-Aldrich, Germany (MES, SUL, TEMB, and TEMB MET); Santa Cruz Biotechnology, Germany (AMBA and MNBA); and Dr. Ehrenstorfer Quality, Germany (CHD and CMBA). The stock solutions $(1 \mathrm{mg} / \mathrm{ml})$ were prepared in methanol and kept under refrigeration. These solutions were stable for 3 months. Acetonitrile, trifluoroacetic acid (TFA), and water (all grade HPLC) were purchased from Merck, Germany.
Acetone, acetonitrile, dichloromethane, methanol, acetic acid (99.5\%), ethyl acetate, potassium chloride, calcium chloride, potassium bichromate, hydrochloric acid (35\%), and sulfuric acid ( $95 \%$ ) (all analytical grade) were purchased from Stanlab, Poland; glucose was delivered by Laboratorium Galenowe, Poland.

\subsection{Experimental design}

\subsubsection{Characteristic of samples}

The soil and sediment samples were collected according to the following standards: ISO 10381-4:2003 (2003) and ISO 5667-15:2009 (2009).

Five soil samples were collected in the fields, which had not been treated with triketones. Sediment samples were collected from two different rivers. The sediments were free of any triketone compounds. Measurement of the $\mathrm{pH}$ of soils and sediments was conducted according to the standard PN ISO 10390:1997 (1997). OC in the collected samples was determined according to the standard PN ISO 14235:2003 (2003). For each sample, the measurements were repeated sixfold. The results (with standard deviation (SD)) of these determinations are presented in Table 2. All the results are expressed per $1 \mathrm{~g}$ of air-dried soil (sediment).

Before recovery studies and degradation experiments, stones and plant fragments were removed, the soils and sediments were air-dried, until the constant mass, and sieved through $0.2 \mathrm{~mm}$ mesh. All calculations and the final results are expressed per $1 \mathrm{~g}$ of air-dried soil (sediment). Samples sterilization was conducted according to Chaabane et al. (2008).

\subsubsection{Samples fortification}

Fortification of the soil and sediment samples with standards was necessary for the estimation of the recovery of extraction procedures and to assess matrix interference. For this purpose, the herbicide and their degradation product stock solutions were diluted in acetone and mixed with sterilized sorbents (soil and sediment samples) to obtain a slurry. For each sorbent type, the standard spiking procedure was replicated threefold. The spiked concentration of analytes was $5 \mu \mathrm{g} / \mathrm{g}$ of sorbent, which corresponded to the herbicide concentration in soil under field conditions, directly after spraying with

Table 2 Physicochemical properties of soils and sediments

\begin{tabular}{|c|c|c|c|c|c|c|}
\hline & Soil 1 & Soil 2 & Soil 3 & Soil 4 & Sediment 1 & Sediment 2 \\
\hline $\mathrm{pH}\left(\mathrm{H}_{2} \mathrm{O}\right)$ & $4.23(0.79)$ & $8.35(0.22)$ & $5.23(0.02)$ & $6.39(0.06)$ & $7.73(0.06)$ & $6.85(0.02)$ \\
\hline $\mathrm{pH}(\mathrm{KCl})$ & $3.72(0.02)$ & $7.65(0.05)$ & $5.33(0.04)$ & $6.81(0.04)$ & $7.43(0.11)$ & $6.43(0.02)$ \\
\hline $\mathrm{pH}\left(\mathrm{CaCl}_{2}\right)$ & $3.28(0.09)$ & $7.27(0.04)$ & $5.42(0.02)$ & $6.72(0.06)$ & $6.96(0.04)$ & $6.53(0.04)$ \\
\hline OC content $(\%)$ & $2.64(0.02)$ & $1.44(0.05)$ & $4.62(0.08)$ & $4.17(0.05)$ & $1.45(0.10)$ & $1.07(0.01)$ \\
\hline
\end{tabular}


herbicide formulation. The obtained mixtures were vigorously agitated to homogenize the dispersion. The dispersion was deposited on a glass surface and left in the dark in a fume cupboard for $4 \mathrm{~h}$. Then, immediately the extraction procedure was conducted.

\subsubsection{Strategy of degradation studies}

In order to assess the influence of OC content and $\mathrm{pH}$ of soil/ sediments on the degradation process of triketones as well as to assess the relative parts of the biotic and abiotic ways in this process, the following procedure for each type of soil sample was applied. The definite amount of soil/sediment (sterilized and unsterilized) slurry spiked individually with precise concentration of one of the triketone herbicides, or their byproducts was deposited on glass sheets (the thickness of the soil layer around $0.5 \mathrm{~cm}$ ). The sheets were left in a fume cupboard in the dark to evaporate the solvent (4 h). Subsequently, each portion of soil was divided into two parts: the first one was exposed to natural solar light in the cycle $16: 8 \mathrm{~h}$ (light to dark); during the experiment, the mean insolation was $900 \mathrm{kWh} / \mathrm{m}^{2}$ and intensity of solar radiation was $700 \mathrm{~W} / \mathrm{m}^{2}$ (according to data published on the Website of the Ministry of Infrastructure and Development, for the Gliwice region), temperature of $20^{\circ} \mathrm{C}$. The second one was kept in the dark, temperature of $20^{\circ} \mathrm{C}$. At the same time, the "blank experiments" for both soil and sediment samples were conducted (sorbents without standards addition).

In the first, fifth, seventh, and twelfth days of experiment and then weekly, $10 \mathrm{~g}$ of each soil and sediment were collected for analyte determination. The whole experiment took 6 weeks and was repeated three times.

\subsubsection{Analytical performance and extraction procedures}

Chromatography was run using a LiChroCART 125-3 Purospher STAR RP-18e, $5 \mu \mathrm{m}$ column. The mobile phase consisted of $0.05 \%$ trifluoroacetic acid in water (A) and acetonitrile (B), in the gradient mode.

Quantification was performed using the internal standard method. A 6-point calibration curves prepared in blank matrix extracts were analyzed in triplicate. Linearity was assumed when the regression coefficient was greater than 0.99 with RSD lower than $15 \%$, value established according to the concentration range used in the calibration curve. The instrumental limits of detection (LOD) were calculated by a signal-to-noise ratio, using the lowest concentration standard. Limits of quantification (LOQ) were computed as three times of LOD.

Extraction of triketones and their degradation products from soil and sediment samples was carried out in three stages. The first one (I STAGE) included solid-liquid extraction (SLE). As an extraction solvent, acetonitrile was applied. Since the extracts contained matrix compounds, which would hinder the chromatographic analysis, therefore, another step of extract purification was necessary. The extract obtained in the first step was extracted with dichloromethane (II STAGE). After phase separation, the organic layer was evaporated to dryness and the residue was dissolved in $\mathrm{HCl}$. To concentrate the extracts and to remove the traces of matrix compounds, the solid-phase extraction (SPE) was applied (III STAGE). Methanol, ethyl acetate, and $4 \%$ acetic acid in acetonitrile were applied as solvents, while copolymer styrene-divinylobenzene was used as a sorbent. The comparison of soil and sediment samples spiked with standards indicated that recoveries of all analytes were acceptable. Measurement precision as indicated by relative standard deviations (RSDs) of replicate analysis of the parallel spiked samples was considered acceptable (RSDs $<15 \%$ ). Coefficients of determination $\left(r^{2}\right)$ of linear regression of external calibration curves were greater than 0.993 .

The recoveries with SD of all analytes are presented in Table 3.

The detailed conditions of chromatographic analysis and selection of extraction conditions are presented in the Electronic supplementary material.

Table 3 Analytical wavelength of analytes and figure of merit of the proposed analytical procedures

\begin{tabular}{|c|c|c|c|c|c|c|c|c|c|c|c|c|c|c|c|}
\hline \multirow[t]{2}{*}{ Analytes } & \multirow{2}{*}{$\begin{array}{l}\text { Analytical } \\
\text { wavelength } \\
(\mathrm{nm})\end{array}$} & \multicolumn{7}{|l|}{ Soil } & \multicolumn{7}{|l|}{ Sediment } \\
\hline & & $\begin{array}{l}\text { Linear } \\
\text { range } \\
(\mu \mathrm{g} / \mathrm{ml})\end{array}$ & $\begin{array}{l}\text { Slope } \\
(\mathrm{SD}) \times 10^{4}\end{array}$ & $\begin{array}{l}\text { Intercept } \\
(\mathrm{SD}) \times 10^{4}\end{array}$ & $r^{2}$ & $\begin{array}{l}\text { LOD } \\
(\mathrm{ng} / \mathrm{g})\end{array}$ & $\begin{array}{l}\text { LOQ } \\
(\mathrm{ng} / \mathrm{g})\end{array}$ & $\begin{array}{l}\text { Recovery } \\
(\% ; \mathrm{SD})\end{array}$ & $\begin{array}{l}\text { Linear } \\
\text { range } \\
(\mu \mathrm{g} / \mathrm{ml})\end{array}$ & $\begin{array}{l}\text { Slope } \\
(\mathrm{SD}) \times 10^{4}\end{array}$ & $\begin{array}{l}\text { Intercept } \\
\text { (SD) } \times 10^{4}\end{array}$ & $r^{2}$ & $\begin{array}{l}\text { LOD } \\
(\mathrm{ng} / \mathrm{g})\end{array}$ & $\begin{array}{l}\text { LOQ } \\
(\mu \mathrm{g} / \mathrm{g})\end{array}$ & $\begin{array}{l}\text { Recovery } \\
(\% ; \mathrm{SD})\end{array}$ \\
\hline MES & 230 & $1.50-100$ & $21(2)$ & $-40(10)$ & 0.9979 & 22 & 66 & $106(7)$ & $1.5-100$ & $24(3)$ & $-11(1)$ & 0.9974 & 20 & 60 & $89(9)$ \\
\hline MNBA & 222 & $1.50-100$ & $35(4)$ & $-38(14)$ & 0.9994 & 5 & 15 & $75(2)$ & $1.0-100$ & $22(1)$ & $9(0.5)$ & 0.9991 & 5 & 15 & $85(9)$ \\
\hline AMBA & 225 & $1.50-100$ & $74(6)$ & $-10(3)$ & 0.9935 & 4 & 12 & $76(4)$ & $1.0-100$ & $35(2)$ & $20(1)$ & 0.9949 & 5 & 15 & $78(7)$ \\
\hline SUL & 240 & $1.50-100$ & $10(1)$ & $9(4)$ & 0.9958 & 15 & 45 & 107 (4) & $6.0-100$ & $9(1)$ & $62(6)$ & 0.9989 & 60 & 180 & $80(10)$ \\
\hline CHD & 256 & $1.50-100$ & $68(9)$ & $44(7)$ & 0.9999 & 11 & 33 & $81(2)$ & $1.0-100$ & $66(9)$ & $-70(7)$ & 0.9911 & 5 & 15 & $90(13)$ \\
\hline CMBA & 222 & $1.50-100$ & $13(1)$ & $33(4)$ & 0.9977 & 13 & 40 & $83(12)$ & $1.5-100$ & $65(12)$ & $74(1)$ & 0.9988 & 20 & 60 & $91(12)$ \\
\hline TEMB & 285 & $1.50-100$ & $12(3)$ & $83(3)$ & 0.9993 & 24 & 72 & $67(2)$ & $1.0-100$ & $13(2)$ & $8(0.2)$ & 0.9981 & 15 & 45 & $98(8)$ \\
\hline TEMB MET & 284 & $1.50-100$ & $20(3)$ & $64(4)$ & 0.9996 & 20 & 60 & $70(4)$ & $1.5-100$ & $21(3)$ & $38(2)$ & 0.9984 & 10 & 30 & $95(7)$ \\
\hline
\end{tabular}




\subsection{Kinetic of triketones degradation}

The dissipation of triketones and their degradation products is generally expressed in terms of $\mathrm{DT}_{50}$, defined as time for disappearance of pesticide to $50 \%$ of its initial concentration. $\mathrm{DT}_{50}$ values were obtained by fitting first-order kinetic to observe degradation patterns, according to the formula (Zhang et al. 2014):

$C=C_{0} e^{-k t}$

$C$ The compound concentration $(\mathrm{mg} / \mathrm{kg})$ at time $t$ (day)

$C_{0}$ The initial concentration of the compound $\left[\mathrm{mg} \mathrm{kg}^{-1}\right]$

$k$ The first-order rate constant $\left(\right.$ day $\left.^{-1}\right)$

$t \quad$ Time (day)

The $\mathrm{DT}_{50}$ for all investigated compounds was calculated separately for each experimental condition according to the formula:

$\mathrm{DT}_{50}=\frac{\ln 2}{k}$

\section{Results and discussion}

\subsection{Influence of soil and sediment $\mathrm{pH}$ on triketones stability}

To exclude the influence of the photolysis as well as the activity of soil microorganisms on the stability of triketones and their degradation products, the discussion on the influence of the $\mathrm{pH}$ on the stability of the analytes was based on the results obtained for the sterilized soils and sediments that were kept in dark.

All triketone herbicides are weak acids ( $\mathrm{p} K_{\mathrm{a}}$ in the range of 3.17-2.98). As the $\mathrm{pH}$ rises, they dissociate from molecular to anionic forms, which are more resistant to hydrolysis and photolysis process (Dyson et al. 2002; Chabbane et al. 2005). Therefore, the stability of MES, SUL, and TEMB was highly influenced by the $\mathrm{pH}$ of sorbent.

Graphically, the influence of soil/sediment $\mathrm{pH}$ on mesotrione stability express as $\mathrm{DT}_{50}$ was presented in Fig. 1.

MES half-live was in the ranges of 5-9 and 2-18 days, for soil and sediments exposed to sunlight and kept in the dark, respectively. The $\mathrm{DT}_{50}$ of SUL and TEMB were in the ranges of 3-4 days (4-7 days in dark) and 6-14 days (10-22 days, in the dark), respectively.

The stability of triketone degradation products were also influenced by a sorbent $\mathrm{pH}$. In general, the lower the $\mathrm{p} K_{\mathrm{a}}$ of the analyte, the more its stability was influenced by the $\mathrm{pH}$ of soil/sediment. CHD was unstable in all investigated sorbents. Its half-life did not exceed 1 day regardless of the type of sorbent.

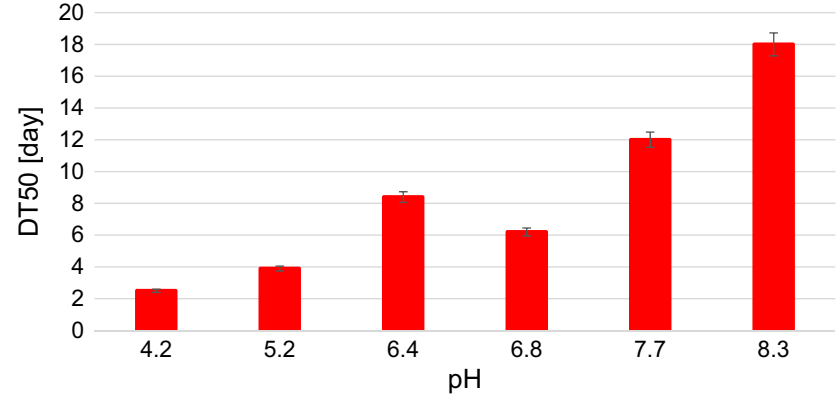

Fig. 1 The influence of soil/sediment $\mathrm{pH}$ on mesotrione $\mathrm{DT}_{50}$. Error bars represent the uncertainty in the determination of the concentration $(n=9)$

This compound is the weaker acid among all investigated compounds ( $\mathrm{p} K_{\mathrm{a}}=5.26$ ); therefore, it was not inclined to form stable anionic form in alkaline sorbents, which reduced its stability. To estimate the influence of the investigated soil/sediment parameters as well as the sunlight, thereby to assess CHD degradation process, the sampling should be conducted in shorter intervals and the extracts should be analyzed by means of liquid chromatography coupled with mass spectrometry detector to determine the structure(s) of CHD degradation product(s).

AMBA with relatively high $\mathrm{p} K_{\mathrm{a}}$ (4.24) may be expected to be unstable; however, it exhibited significant stability $\left(\mathrm{DT}_{50}\right.$ 4-28 days, exposed to sunlight, 12-46 days in the dark) in investigated soil and sediments. It was probably caused by its high (among investigated compounds) $\log \mathrm{P}(0.31)$, indicating that this compound possessed higher affinity to bind with soil/ sediment particles.

Many researchers indicate adsorption as a fundamental process responsible for pesticide migration in soils, but there seems to be some controversy regarding the mechanisms by which these substances are bound (Chefetz et al. 2004; Pateiro-Moure et al 2009; Rani and Juwarkar 2010; Álvarez et al. 2013; Liu et al. 2013). Since the AMBA half-life was not influenced by the OC content in soil and sediments, it may be concluded that the complex between this compound and inorganic fraction of sorbents was created. Ionogenic compounds, such as AMBA can sorb to soils via electrostatic attraction and surface complexation with soil iron and aluminum oxides. The interaction of pesticide organic anions with quartz/silica is limited due to electrostatic repulsion between the anion and the negatively charged silica surface and the inertness of silanol groups $(-\mathrm{SiOH})$ to ligand exchange. Therefore, the mineralogy of soil/sediment iron and aluminum oxides and clays play a dominant role in the controlling of the AMBA fate in investigated sorbents (Vasudevan et al 2002).

AMBA, MNBA, and CMBA show great resemblance in terms of structure. However, CMBA and MNBA contain electron-withdrawing substituents at ortho-position (deactivating group $-\mathrm{Cl},-\mathrm{NO}_{2}$ ), whereas AMBA possess electron-donating group substituents at ortho-position ($\mathrm{NH}_{2}$ ), which is capable of forming ion pairs. This structural 
difference may be favorable to create complex with soil/ sediment mineral compounds resulting in an increase of AMBA persistence in sorbents.

In Fig. 2, the comparison of $\mathrm{DT}_{50}$ of triketone degradation products in the most acidic and alkaline soil was presented. In the figure the half-lives of parent compounds were also placed. In all cases, the stability of the herbicide was significantly lower than the stability of its degradation products (with exception of CHD).

For samples exposed to sunlight (both sterilized and unsterilized), the same relation was observed; however, the stability of all compounds was lower, because of the activity of microorganisms and photolysis.

The direct and induced degradation photochemical processes influenced the stability of triketones. The natural soil organic matter can act, under sunlight excitation, as a photosensitizer through the generation of various oxygen species thereby accelerating the degradation of triketones. Although the inner filter effect, which may occur when an organic compounds is entrapped inside a soil particle, and photochemical quenching of electronically excited states by intramolecular energy transfer to various soil components, the induced degradation seemed to play a dominant role in photodegradation of triketones (Rasen et al. 1997; Chan and Chu 2005; Menager and Sarakha 2013; Siampiringue et al. 2014).

\subsection{The influence of $\mathrm{OC}$ on triketone stability}

No evident correlation between OC of soils/sediments and stability of triketones and their degradation products was
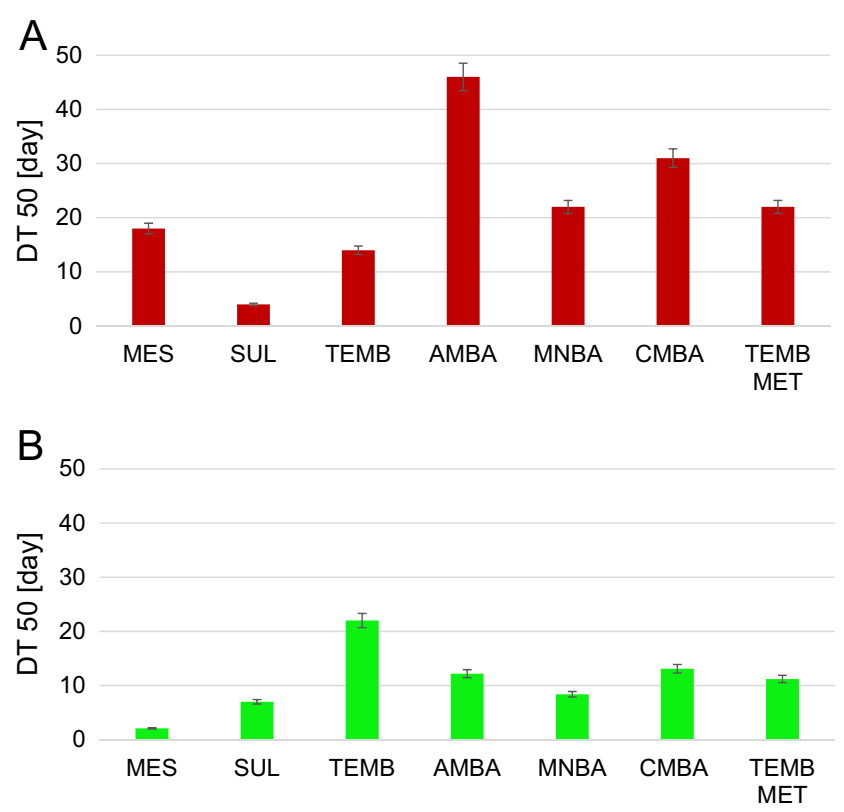

Fig. $2 \mathrm{DT}_{50}$ of triketones and their degradation products in the most alkaline soil-Soil 2 (a) and in the most acidic soil-Soil 1 (b). Error bars represent the uncertainty in the determination of the concentration $(n=9)$ observed. To assess unambiguously the relation between OC and the analyte stability, more soil and sediment samples with different physicochemical characteristic should be analyzed.

\subsection{Influence of microorganism on mesotrione stability in soils}

The comparison of MES degradation in unsterilized and sterilized soil samples was conducted. In Fig. 3, the changes of MES in unsterilized Soil 3 exposed to sunlight (Fig. 3a), sterilized Soil 3 exposed to sunlight (Fig. 3b), and unsterilized Soil 3 kept in the dark (Fig. 3c) were presented. For the sterilized soil samples, $\mathrm{DT}_{50}$ ranged from 9 to 15 days. The degradation process of MES was correlated with the formation of its degradation product, MNBA. Soil microorganisms accelerated the degradation of MES to MNBA; however, the sunlight had the greatest impact on the formation of MNBA from MES.

In the 35th day of experiment in the soil samples exposed to sunlight, the reduction of the MNBA concentration was observed. At the same time, AMBA - the final product of MES degradation was detected in soils; however, its concentration did not exceed the LOQ.

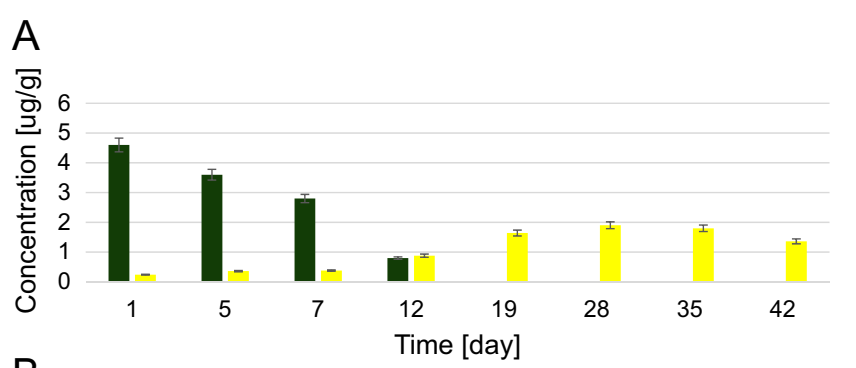

$B$
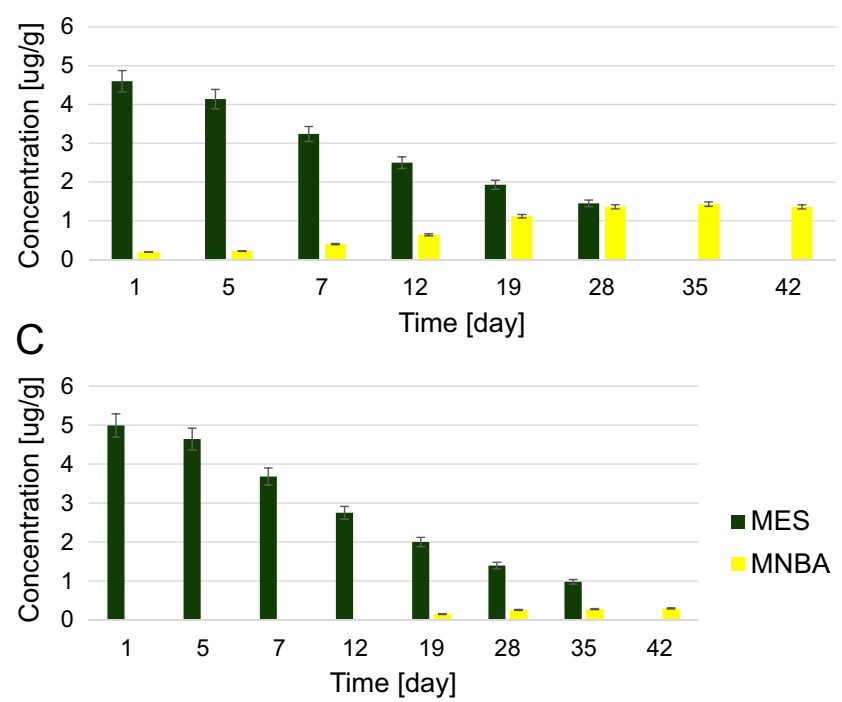

Fig. 3 The changes of MES in unsterilized soil 3 exposed to sunlight (a), sterilized Soil 3 exposed to sunlight (b), and unsterilized Soil 3 kept in dark (c). Error bars represent the uncertainty in the determination of the concentration $(n=9)$ 


\section{Conclusions}

1. All investigated degradation products exhibited higher stability in both soils and sediments than their parent compounds.

2. Stability of triketone herbicides and their byproducts was correlated with $\mathrm{pH}$ of soil and sediments - the more alkaline the sorbent, the more stable these compounds will be. The investigated compounds dissociated from molecular to anionic form as the $\mathrm{pH}$ rises. The anionic forms were more resistant to hydrolysis and photolysis processes.

3. The soil microflora accelerated the degradation of MES and formation its degradation product MNBA.

4. In all investigated soils and sediments, the sunlight accelerated the degradation process of triketones and their degradation products.

Open Access This article is distributed under the terms of the Creative Commons Attribution 4.0 International License (http:// creativecommons.org/licenses/by/4.0/), which permits unrestricted use, distribution, and reproduction in any medium, provided you give appropriate credit to the original author(s) and the source, provide a link to the Creative Commons license, and indicate if changes were made.

\section{References}

Álvarez M, du Mortier C, Fernández Cirelli A (2013) Behavior of insecticide chlorpyrifos on soils and sediments with different organic matter content from Provincia de Buenos Aires, República Argentina. Water Air Soil Pollut 224:1453-1459

Anderson BS, Hunt JW, Phillips BM, Nicely PA, Gilbert KD, de Vlaming V (2003) Ecotoxicologic impacts of agricultural drain water in the Salinas River, California, USA. Environ Toxicol Chem 22:23732384

Asensio-Ramos M, Hernández-Borges J, Ravelo-Pérez LM (2010) Evaluation of a modified QuEChERS method for the extraction of pesticides from agricultural, ornamental and forestal soils. Anal Bioanal Chem 396:2307-2319

Barchanska H, Rusek M, Szatkowska A (2012) New procedures for simultaneous determination of mesotrione and atrazine in water and soil. Comparison of the degradation processes of mesotrione and atrazine. Environ Monit Assess 184:321-334

Barchanska H, Kowalska A, Poloczek B (2014) Extraction procedures for the study of phytotoxicity and degradation processes of selected triketones in a water ecosystem. Environ Sci Pollut Res 21:47514758

Batisson I, Crouzet O, Besse-Hoggan P, Sancelme M, Mangot J-F, Mallet C, Bohatier J (2009) Isolation and characterization of mesotrionedegrading Bacillus sp. from soil. Environ Pollut 157:1195-1201

Bonnet JL, Bonnemoy F, Dusser M, Bohatier J (2008) Toxicity assessment of the herbicides sulcotrione and mesotrione toward two reference environmental microorganisms: Tetrahymena pyriformis and Vibrio fischeri. Arch Environ Contam Toxicol 55:576-583

Calvayrac C, Bontemps N, Nouga-Bissoue A, Romdhane S, Coste C-M, Cooper J-F (2013) Photolysis of tembotrione and its main by- products under extreme artificial conditions: comparison with another $\beta$-triketone herbicide. Sci Total Environ 452-453:227-232

Chaabane H, Cooper JF, Azouzi L, Coste CM (2005) Influence of soil properties on the adsorption-desorption of sulcotrione and its hydrolysis metabolites on various soils. J Agric Food Chem 53:40914095

Chaabane H, Vulliet E, Jouxc F, Lantoine F, Conan P, Cooper J-F, Coste C-M (2007) Photodegradation of sulcotrione in various aquatic environments and toxicity of its photoproducts for some marine microorganisms. Water Res 41:1781-1789

Chaabane H, Vulliet E, Calvayrac C, Coste CM, Cooper JF (2008) Behaviour of sulcotrione and mesotrione in two soils. Pest Manag Sci 64:86-93

Chan KH, Chu W (2005) Effect of humic acid on the photolysis of the pesticide atrazine in a surfactant-aided soil-washing system in acidic condition. Water Res 39:2154-2166

Chefetz B, Bilkis YI, Polubesova T (2004) Sorption-desorption behavior of triazine and phenylurea herbicides in Kishon river sediments. Water Res 38:4383-4394

Cherrier R, Boivin A, Perrin-Ganier C, Schiavon M (2005) Sulcotrione versus atrazine transport and degradation in soil columns. Pest Manag Sci 61:899-904

Cropnosis Agrochemical Database (2010). www.cropnosis.com/ marketing/products/databases. Accessed 24 Mar 2014

Crouzet O, Batisson I, Besse-Hoggan P, Bonnemoy F, Bardot C, Poly F, Bohatier J, Mallet C (2010) Response of soil microbial communities to the herbicide mesotrione: a dose-effect microcosm approach. Soil Biol Biochem 42:193-202

Dyson JS, Beulke S, Brown CD, Lane MCGM (2002) Adsorption and degradation of the weak acid mesotrione in soil and environmental fate implications. Organic compounds in the environment. J Environ Qual 31:613-618

Feria-Reyes R, Medina-Armenta P, Teuli-Leon M, Garcia-Jimenez G, Gonzalez I (2011) A new approach for atrazine desorption, extraction and detection from a clay-silty soil sample. Am J Anal Chem 2: $63-68$

Hutta R, Góra R, Halkom R, Chalanyovam M (2011) Some theoretical and practical aspects in the separation of humic substances by combined liquid chromatography methods. J Chromatogr A 1218:89468957

ISO 10381-4:2003 (2003) Soil quality—sampling — part 4: guidance on the procedure for investigation of natural, near-natural and cultivated sites

ISO 5667-15:2009 (2009) Water quality - sampling — part 15: guidance on the preservation and handling of sludge and sediment samples

Li Y, Lin T, Yanwen Y, Zhang L, Guo Z (2013) Distribution and sources of organochlorine pesticides in sediments of the Xiangjiang River, south-central China. Environ Monit Assess 185:8861-8871

Liu Z, He Y, Xu J, Zeng F (2013) How do amorphous sesquioxides affect and contribute to butachlor retention in soils. J Soils Sediments 13: $617-628$

Lu JL (2011) Insecticide residues in eggplant fruits, soil, and water in the largest eggplant-producing area in the Philippines. Water Air Soil Pollut 220:413-422

Mamy L, Vrignaud P, Cheviron N, Perreau F, Belkacem M, Brault A (2011) No evidence for effect of soil compaction on the degradation and impact of isoproturon. Environ Chem Lett 9:145-150

Menager M, Sarakha M (2013) Simulated solar light phototransformation of organophosphorus azinphos methyl at the surface of clays and goethite. Environ Sci Technol 47:765-772

Mountacer H, Atifi A, Wong-Wah-Chung P, Sarakha M (2014) Degradation of the pesticide carbofuran on clay and soil surfaces upon sunlight exposure. Environ Sci Pollut Res 21:3443-3451

Murati M, Oturan N, Aaron J-J, Dirany A, Tassin B, Zdravkovski Z, Oturan MA (2012) Degradation and mineralization of sulcotrione 
and mesotrione in aqueous medium by the electro-Fenton process: a kinetic study. Environ Sci Pollut Res 19:1563-73

Murati M, Oturan N, Zdravkovski Z, Stanoeva JP, Aaron SE, Aaron J-J, Oturan MA (2014) Application of the electron-Fenton process to mesotrione aqueous solutions: kinetics, degradation pathways, mineralization, and evolution of toxicity. Maced J Chem Chem Eng 33: $121-137$

Pateiro-Moure M, Pérez-Novo C, Arias-Estévez M, Rial-Otero R, SimalGándar J (2009) Effect of organic matter and iron oxides on quaternary herbicide sorption-desorption in vineyard-devoted soils. J Colloid Interface Sci 333:431-438

PN ISO 10390:1997 (1997) Soil quality-determination of $\mathrm{pH}$

PN ISO 14235:2003 (2003) Soil quality-determination of organic carbon by sulfchromic oxidation

Rani R, Juwarkar A (2010) Adsorption of phorate, an organophosphorus pesticide on vertisol. Arch Environ Contam Toxicol 58:927-934

Rosen D, Tel-Or E, Hadar Y, Chen Y (1997) Modern agriculture and the environment. Springer, doi: 10.1007/978-94-011-5418-5
Sánchez-Avila J, Fernandez-Sanjuan M, Vicente J, Lacorte S (2011) Development of a multi-residue method for the determination of organic micropollutants in water, sediment and mussels using gas chromatography-tandem mass spectrometry. J Chromatogr A 1218: 6799-6811

Siampiringue M, Chung WW, Koriko M, Tohangbedji G, Sarakha M (2014) Clay and soil photolysis of the pesticides mesotrione and metsulfuron methyl. Appl Environ Soil Sci 2014:1-8

Smalling KL, Kuivila KM, Orlando JL, Phillips BM, Anderson BS, Siegler K (2013) Environmental fate of fungicides and other current-use pesticides in a central California estuary. Mar Pollut Bull 73:144-153

Vasudevan D, Cooper E, Exem OL (2002) Sorption-desorption of ionogenic compounds at the mineral-water interface: study of metal oxide-rich soils and pure-phase minerals. Environ Sci Technol 36:501-511

Zhang H, Wu J, Zhang Y, Wang K (2014) Dissipation of trinexapac-ethyl and its metabolite in wheat field ecosystems and microbial degradation in soil. Int J Environ Anal Chem 94:1375-1387 